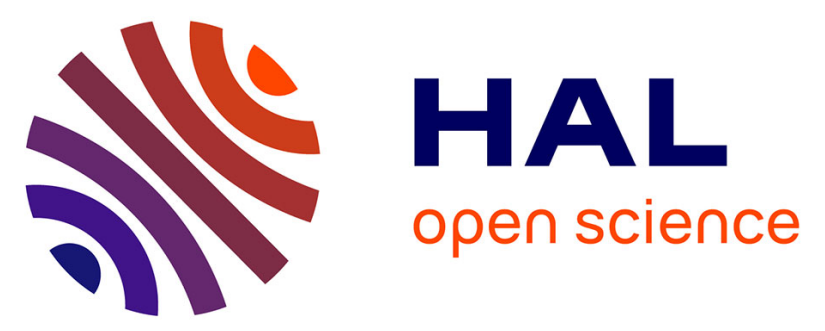

\title{
Inner surface modification of halloysite nanotubes and its influence on morphology and thermal properties of polystyrene/polyamide-11 blends
}

Mohamed Sahnoune, Aurélie Taguet, Belkacem Otazaghine, Mustapha Kaci, José-Marie Lopez-Cuesta

\section{To cite this version:}

Mohamed Sahnoune, Aurélie Taguet, Belkacem Otazaghine, Mustapha Kaci, José-Marie LopezCuesta. Inner surface modification of halloysite nanotubes and its influence on morphology and thermal properties of polystyrene/polyamide-11 blends. Polymer international, 2017, 66 (2), pp.300312. 10.1002/pi.5266 . hal-02892707

\section{HAL Id: hal-02892707 https://hal.science/hal-02892707}

Submitted on 15 Dec 2020

HAL is a multi-disciplinary open access archive for the deposit and dissemination of scientific research documents, whether they are published or not. The documents may come from teaching and research institutions in France or abroad, or from public or private research centers.
L'archive ouverte pluridisciplinaire HAL, est destinée au dépôt et à la diffusion de documents scientifiques de niveau recherche, publiés ou non, émanant des établissements d'enseignement et de recherche français ou étrangers, des laboratoires publics ou privés. 


\title{
Inner surface modification of halloysite nanotubes and its influence on morphology and thermal properties of polystyrene/polyamide-11 blends
}

\author{
Mohamed Sahnoune, ${ }^{a, b}$ Aurélie Taguet, ${ }^{b}$ Belkacem Otazaghine, ${ }^{\text {b* }}$ Mustapha \\ Kaci $^{\mathrm{a}}$ and José-Marie Lopez-Cuesta ${ }^{\mathrm{b}}$
}

\begin{abstract}
The asymmetry of halloysite surface chemistry was used to perform a selective modification of its inner surface via grafting of a synthesized styrene/(methacryloyloxy)methyl phosphonic acid copolymer. Fourier transform infrared spectroscopy, thermogravimetric analysis (TGA) and pyrolysis gas chromatography/mass spectrometry were used to evidence and quantify the grafting. Then, raw and hybrid nanoparticles were incorporated in polystyrene (PS)/polyamide-11 (PA11) blends (80/20 and $60 / 40 \mathrm{wt} \%$ ). Scanning electron micrographs showed differences in localization of the halloysite nanotubes (HNTs), since raw halloysite is concentrated in the PA11 phase while modified halloysite is also located at the PS/PA11 interface, leading to a better interfacial adhesion between PS and PA11. An inhibiting effect of modified halloysite on PA11 coalescence was evidenced by measuring the particle size distribution of the extracted nodules. Moreover, the presence of modified halloysite at the interface shows an improvement in terms of thermal stability as observed by TGA, but with no significant effects on PA11 crystallization behaviour as shown by differential scanning calorimetry results. Rheological measurements were carried out to study the influence of the surface modification of halloysite on the blend morphology. A gel-like behaviour was observed for the (60/40 wt\%) HNTs reinforced composition that was enhanced in the case of $10 \%$ functionalized halloysite.
\end{abstract}

Keywords: halloysite nanotubes; selective functionalization; blend morphology; blend compatibilization

\section{INTRODUCTION}

Blending of polymers is a commonly used and well-known route to obtain new high-performance materials with various properties. ${ }^{1,2}$ However, in the case of immiscible polymers, blends exhibit a narrow interface with high interfacial tension and weak chemical/physical interactions and thus poor properties. ${ }^{3}$ Therefore, compatibilization is the main challenge in order to achieve polymer blends with improved properties. ${ }^{4}$ To overcome this immiscibility, different compatibilizing agents can be used, such as block or grafted copolymers of appropriate chemical structure, ${ }^{5,6}$ reactive compatibilizers ${ }^{7,8}$ and more recently solid filler nanoparticles like fumed silica, ${ }^{9,10}$ graphene, ${ }^{11}$ titanium oxide $^{12}$ or organomodified clays. ${ }^{13,14}$ Indeed, ternary systems of two polymers with incorporation of an inorganic filler have attracted a great deal of interest in the last few years, not only for their superior thermal and mechanical properties, ${ }^{15-17}$ but also for the stabilizing and compatibilizing effect of the incorporated nanoparticles. ${ }^{18,19}$ The compatibilizing effect occurs when the filler is localized at the interface of the two polymers ${ }^{20,21}$ and this final localization depends on several thermodynamic and kinetic parameters including incorporation sequence, ${ }^{9,22}$ mixing time, ${ }^{23,24}$ viscosity ratio of the two polymers ${ }^{25-27}$ and nanoparticle characteristics such as size, shape ${ }^{28}$ and surface chemistry. ${ }^{29,30}$
Polyamide-11 (PA11) and polystyrene (PS) are two widely and commonly used polymers with large field of applications from automotive to food packaging. So, a PS/PA11 blend combining the desirable properties of the two constituents will be welcomed. Many authors have worked on compatibility enhancement between PAs and PS. First, they focused on the use of PS bearing specific functions: acrylic acid, ${ }^{31}$ manganese sulfonate ${ }^{32}$ or maleic anhydride. ${ }^{33}$ Then the focus was on direct in situ polymerization of the blend ${ }^{34}$ and more recently on the utilization of mineral nanofillers such as silica and montmorillonite. ${ }^{35,36}$ Halloysite nanotubes (HNTs) are a mineral of the kaolin group with the chemical composition $\mathrm{Al}_{2} \mathrm{Si}_{2} \mathrm{O}_{5}(\mathrm{OH})_{4} \cdot n \mathrm{H}_{2} \mathrm{O}$. They have many advantages such as biocompatibility, thermal stability and reinforcing effect, ${ }^{37}$ leading to a wide range of applications. Various polymer/halloysite nanocomposite systems have been reported, with, as direct

\footnotetext{
* Correspondence to: B Otazaghine, Centre des Matériaux des Mines d'Alès (C2MA), Ecole des Mines d'Alès, 6 avenue de Clavières, 30319Alès cedex, France. E-mail: belkacem.otazaghine@mines-ales.fr

a Laboratoire des Matériaux Polymères Avancés (LMPA), Université de Bejaia, 06000, Algeria

b Centre des Matériaux des Mines d'Alès (C2MA), Ecole des Mines d'Alès, 6 avenue de Clavières, 30319 Alès cedex, France
} 

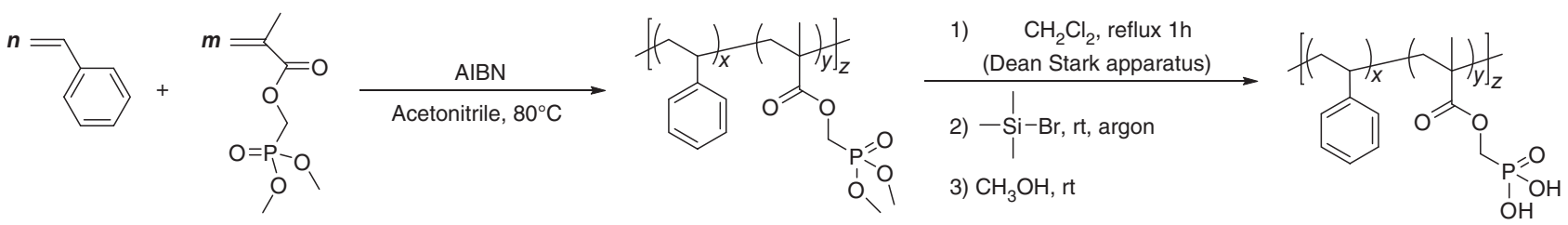

Figure 1. Schematic representation of $\mathrm{P}\left(\mathrm{S}-\mathrm{co}^{-M A P C} \mathrm{M}_{1}(\mathrm{OH})_{2}\right)$ synthesis. ${ }^{47}$

consequences, enhancements in mechanical properties like Young's modulus, toughness and tensile strength, improvement of thermal stability, nucleic effect and also flame-retardant behaviour. ${ }^{38-40}$ Added to these enhancing effects, halloysite possesses a unique tubular structure with aluminol groups at the inner surface and silanol ones at the outer. This asymmetry of composition leads to differences of reactivity, which allows selective modification of halloysite particles to be performed. Indeed, the reactivity between aluminol groups of HNTs and copolymers bearing phosphonic functions allows the inner surface of HNTs to be grafted. ${ }^{41,42}$ There are few reported works in the literature on the use of halloysite as a compatibilizing agent in immiscible polymer blends. ${ }^{43,44}$ HNTs modified with $N$-( $\beta$-aminoethyl)$\gamma$-aminopropyltrimethoxysilane were used to compatibilize a polyoxymethylene/polypropylene (PP) blend ${ }^{43}$ and a syndiotactic PS/liquid crystalline polymer blend. ${ }^{44}$ HNTs were also used with maleated styrene-ethylene/butylene-styrene to improve the performances of a PP/poly(ethylene terephthalate) blend. ${ }^{45}$ However, there are no reports about the use of inner-surfacefunctionalized halloysite in immiscible polymer blends.

The main objective of the work reported here was to investigate the potential of halloysite, after its inner surface modification by grafting of copolymer chains, as a suitable filler and compatibilizing agent for a PS/PA11 blend. To this aim, halloysite inner surface was modified by grafting of a styrene/(methacryloyloxy)methyl phosphonic acid (P(S-CO-MAPC $\left.1(\mathrm{OH})_{2}\right)$ ) copolymer, which was synthetized in our laboratory. Then, $80 / 20$ and co-continuous $60 / 40$ PS/PA11 blends filled with raw and modified HNTs were prepared by melt compounding.

\section{EXPERIMENTAL}

\section{Materials}

PA11 (Rilsan ${ }^{\circledR}$ LMNO) was kindly supplied by Arkema. This grade is free of any stabilizers or additives. Its mean molecular weight $M_{\mathrm{n}}=22000 \mathrm{~g} \mathrm{~mol}^{-1}$ and average molar weight $=51000 \mathrm{~g} \mathrm{~mol}^{-1}$ with a density of $1.02 \mathrm{~g} \mathrm{~cm}^{-3}$. PS (CRISTAL 1340) was purchased from Total Petrochemicals. It is an amorphous PS with a high molecular weight, a melt flow index of $4 \mathrm{~g}(10 \mathrm{~min})^{-1}$ (with $5 \mathrm{~kg}$ at $200^{\circ} \mathrm{C}$ ) and a density of $1.05 \mathrm{~g} \mathrm{~cm}^{-3}$. Raw halloysite (referenced as $\mathrm{Hal}$ ) was derived from Djebel Debbagh deposit (eastern region of Algeria). Styrene was purchased from Sigma Aldrich, azobisisobu-

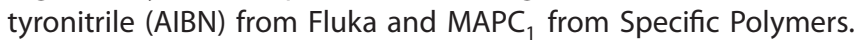
Before use, HNTs and polymer pellets were dried under vacuum at $80^{\circ} \mathrm{C}$ for $24 \mathrm{~h}$ and overnight, respectively, to remove traces of moisture.

\section{Synthesis of grafting agent}

The first step consisted of a radical copolymerization of styrene and MAPC $_{1}$ under argon atmosphere. ${ }^{46}$ Into a $100 \mathrm{~mL}$ flask fitted with a condenser, $15 \mathrm{~g}\left(1.4 \times 10^{-1} \mathrm{~mol}\right)$ of styrene, $3.3 \mathrm{~g}\left(1.6 \times 10^{-2} \mathrm{~mol}\right)$ of MAPC $_{1}, 0.26 \mathrm{~g}\left(1.6 \times 10^{-3} \mathrm{~mol}\right)$ of AIBN and $20 \mathrm{~g}$ of acetonitrile were introduced. Argon was bubbled through the mixture for $15 \mathrm{~min}$. The mixture was then stirred and heated at $80^{\circ} \mathrm{C}$ for $15 \mathrm{~h}$. After reaction, the polymer, $\mathrm{P}\left(\mathrm{S}-\mathrm{CO}-\mathrm{MAPC} \mathrm{C}_{1}\right)$, was purified by precipitation in methanol.

The second step consisted of hydrolysis of the phosphonate groups of the copolymer obtained in the first step. Into a $100 \mathrm{~mL}$ two-necked flask equipped with a Dean-Stark apparatus, $10 \mathrm{~g}$ of copolymer $\mathrm{P}\left(\mathrm{S}-\mathrm{CO}_{-} \mathrm{MAPC}_{1}\right)(90 / 10 \mathrm{~mol} \%)$ and $40 \mathrm{~mL}$ of dichloromethane were introduced under inert atmosphere. The mixture was degassed by bubbling argon for $15 \mathrm{~min}$, stirred and heated at dichloromethane reflux for $1 \mathrm{~h}$ (water was eliminated by the Dean-Stark apparatus). The mixture was then cooled to room temperature and $2.7 \mathrm{~g}\left(1.8 \times 10^{-2} \mathrm{~mol}\right)$ of bromotrimethylsilane was added dropwise. After $15 \mathrm{~h}$ the solvent was partially eliminated under vacuum, before precipitation of the copolymer $\mathrm{P}\left(\mathrm{S}-\mathrm{CO}_{-} \mathrm{MAPC}_{1}(\mathrm{OH})_{2}\right)$ in methanol. A schematic representation of the grafting agent synthesis process is shown in Fig. 1.

\section{Halloysite modification}

Into a $100 \mathrm{~mL}$ flask fitted with a condenser were introduced $5 \mathrm{~g}$ of halloysite, $0.5 \mathrm{~g}$ of $\mathrm{P}\left(\mathrm{S}-\mathrm{CO}-\mathrm{MAPC}_{1}(\mathrm{OH})_{2}\right)$ and $50 \mathrm{~mL}$ of toluene. The mixture was then stirred and heated at solvent reflux for $15 \mathrm{~h}$. After the reaction, the mixture was centrifuged ( $5000 \mathrm{rpm}$ ) to eliminate the liquid phase and washed twice with tetrahydrofuran (THF) and twice with acetone. Finally, the obtained modified halloysite (referenced as Hal-M) was filtered and dried under vacuum before characterization and use. The reaction between halloysite and $\mathrm{P}\left(\mathrm{S}-\mathrm{CO}-\mathrm{MAPC}_{1}(\mathrm{OH})_{2}\right)$ is schematically represented in Fig. 2.

\section{Sample preparation}

Raw and modified halloysite were incorporated at 3 and $10 \mathrm{wt} \%$ in PS/PA11 blends with two weight ratios (80/20 and 60/40), as summarized in Table 1 . The samples were prepared by melt mixing under nitrogen atmosphere in a twin-screw mini-extruder DSM (Xplore) with a screw length of $135 \mathrm{~mm}$ and a chamber volume of $15 \mathrm{~cm}^{3}$. The temperature was set at $240{ }^{\circ} \mathrm{C}$ and the screw speed was 60, 120 and $40 \mathrm{rpm}$ during incorporation ( $1 \mathrm{~min}$ ), mixing ( $4 \mathrm{~min}$ ) and extrusion (almost $2 \mathrm{~min}$ ), respectively. To avoid handling of volatile dry nanoparticles, a first solvent casting step was used to incorporate the HNTs into PS. To achieve that, $1 \mathrm{~g}$ of PS was dissolved in $15 \mathrm{~mL}$ of THF at room temperature before the introduction of the HNTs. The filler was then ultrasonically dispersed in the mixture. The solvent was then evaporated and the obtained film was dried under vacuum at $80^{\circ} \mathrm{C}$ overnight. The PS film containing HNTs was first pre-compounded with the rest of the PS pellets for $1 \mathrm{~min}$. After pelletizing, the granules were dried under vacuum at $80^{\circ} \mathrm{C}$ overnight and then injection-moulded onto discs for rheological analyses using a mini injection-moulding machine (MERCATOR, Zamak). The barrel temperature was $240^{\circ} \mathrm{C}$ and the mould temperature was kept at $80^{\circ} \mathrm{C}$. Holding pressure and injection time were 2 bar $(200 \mathrm{kPa})$ and $10 \mathrm{~s}$, respectively. 


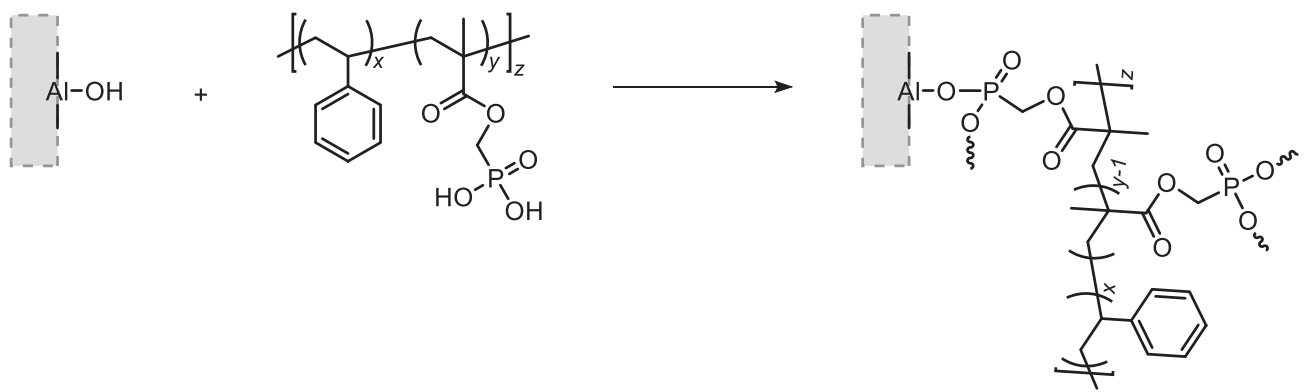

Figure 2. Schematic representation of reaction between halloysite and $\mathrm{P}\left(\mathrm{S}-\mathrm{CO}-\mathrm{MAPC} \mathrm{C}_{1}(\mathrm{OH})_{2}\right)$.

\begin{tabular}{|c|c|c|c|}
\hline Sample & PS/PA11 & $\mathrm{Hal}(\mathrm{wt} \%)$ & Hal-M (wt\%) \\
\hline $80 / 20$ & $80 / 20$ & 0 & 0 \\
\hline $80 / 20 \mathrm{H} 3$ & $80 / 20$ & 3 & 0 \\
\hline 80/20 HM3 & $80 / 20$ & 0 & 3 \\
\hline 80/20 H10 & $80 / 20$ & 10 & 0 \\
\hline 80/20 HM10 & $80 / 20$ & 0 & 10 \\
\hline $60 / 40$ & $60 / 40$ & 0 & 0 \\
\hline $60 / 40 \mathrm{H} 3$ & $60 / 40$ & 3 & 0 \\
\hline 60/40 HM3 & $60 / 40$ & 0 & 3 \\
\hline $60 / 40 \mathrm{H} 10$ & $60 / 40$ & 10 & 0 \\
\hline 60/40 HM10 & $60 / 40$ & 0 & 10 \\
\hline
\end{tabular}

\section{Annealing and selective extraction}

Annealing was performed using an oven under nitrogen flow. Around $50 \mathrm{mg}$ of blend was annealed at process temperature $\left(240^{\circ} \mathrm{C}\right)$ for $10 \mathrm{~min}$. Then the annealed materials were immersed into $20 \mathrm{~mL}$ of THF at room temperature without stirring overnight to remove PS. Finally, PA11 nodules were purified by three washing-centrifugation cycles using THF solvent and then collected for analysis.

\section{Characterization}

${ }^{1}$ H NMR spectroscopy

NMR spectra were recorded with Bruker AC 400 instruments, using deuterated chloroform as the solvent and tetramethylsilane as the references for ${ }^{1} \mathrm{H}$ nuclei. Chemical shifts are given in parts per million (ppm). The experimental conditions for recording ${ }^{1} \mathrm{H}$ NMR spectra were as follows: flip angle, $90^{\circ}$; acquisition time, $4.5 \mathrm{~s}$; pulse delay, 2 s; number of scans, 16.

\section{Fourier transform infrared (FTIR) spectroscopy}

The modifications to the chemical structure of halloysite after grafting were investigated using FTIR spectroscopy, performed using an IFS 66 spectrometer (Bruker). Samples were dispersed in $\mathrm{KBr}$ pellets (1:99 ratio) and spectra were obtained by collecting 64 scans between 400 and $4000 \mathrm{~cm}^{-1}$ with a resolution of $2 \mathrm{~cm}^{-1}$.

\section{Pyrolysis gas chromatography/mass spectrometry (Py-GC/MS)}

A Pyroprobe 5000 pyrolyser (CDS analytical) was used to flash pyrolyse the samples in a helium environment. This pyrolyser was supplied with an electrically heated platinum filament. One coil probe enabled the pyrolysis of samples $(<1 \mathrm{mg})$ placed in a quartz tube between two pieces of rockwool. The sample was heated at $900^{\circ} \mathrm{C}$. The temperature was held for $15 \mathrm{~s}$ then the gases were drawn to the gas chromatograph for $5 \mathrm{~min}$. The Pyroprobe 5000 was interfaced to a 450-GC chromatograph (Varian) by means of a chamber heated at $270^{\circ} \mathrm{C}$. In the oven the initial temperature of $70^{\circ} \mathrm{C}$ was raised to $250^{\circ} \mathrm{C}$ at $10^{\circ} \mathrm{C} \mathrm{min}^{-1}$. The column was a Varian Vf- $5 \mathrm{~ms}$ capillary column $(30 \mathrm{~m} \times 0.25 \mathrm{~mm}$; thickness of $0.25 \mu \mathrm{m})$ and helium $\left(1 \mathrm{~L} \mathrm{~min}^{-1}\right)$ was used as the carrier gas. A split ratio was set to 1:50. The gases were introduced from the GC transfer line to the ion trap analyser of the 240-MS mass spectrometer (Varian) through the direct-coupled capillary column.

\section{Thermogravimetric analysis}

TGA was performed using a thermogravimetric analyser (Setsys Evolution, Setaram). In order to remove all the physisorbed water of the HNTs, an isothermal step $\left(10 \mathrm{~min}, 110^{\circ} \mathrm{C}\right)$ was performed before starting the analysis and then the samples were heated to $900^{\circ} \mathrm{C}$ at a heating rate of $10^{\circ} \mathrm{C} \mathrm{min}^{-1}$. While the blend samples were heated to $600^{\circ} \mathrm{C}$ at $10^{\circ} \mathrm{C} \mathrm{min}^{-1}$. Measurements were carried out under nitrogen atmosphere with a flow rate of $20 \mathrm{~mL} \mathrm{~min}^{-1}$ for samples of approximately $20 \mathrm{mg}$.

\section{Contact angle measurements}

Contact angle measurements were carried out by depositing a liquid drop with controlled volume on the sample surface. The contact angle $\theta$ between the liquid and the substrate was measured using a KRÜSS Drop Shape Analyzer DSA30 goniometer apparatus. Thin flat discs of halloysite were prepared using a compression moulding laboratory press at $0{ }^{\circ} \mathrm{C}$ and $30 \mathrm{bar}(3 \mathrm{MPa})$. Then, contact angle measurements between sample surface and two liquids (water and diiodomethane) with different dispersive $\left(\gamma_{L}^{\mathrm{D}}\right)$ and polar $\left(\gamma_{L}^{\mathrm{P}}\right)$ contributions were performed three times for each surface-solvent pair. The dispersive $\left(\gamma_{S}^{\mathrm{D}}\right)$ and polar $\left(\gamma_{\mathrm{S}}^{\mathrm{P}}\right)$ contributions to the surface energy of samples were calculated according to Eqn (1) using the Owens-Wendt model: ${ }^{48}$

$$
\gamma_{L}(1+\cos \theta)=2 \sqrt{\gamma_{S}^{d} \gamma_{L}^{d}}+2 \sqrt{\gamma_{S}^{p} \gamma_{L}^{p}}
$$

where $\gamma_{L}^{d}$ and $\gamma_{L}^{p}$ are known for the two different liquids used.

\section{Solvent dispersion test}

A dispersion test in a water-toluene mixture was also completed on Hal and Hal-M. An amount of $5 \mathrm{mg}$ of clay was introduced in $10 \mathrm{~mL}$ of water and ultrasonically dispersed for $5 \mathrm{~min}$. Toluene $(10 \mathrm{~mL})$ was then added and the whole was mixed ultrasonically for another $5 \mathrm{~min}$. The mixtures were left for a week and an image was obtained. 


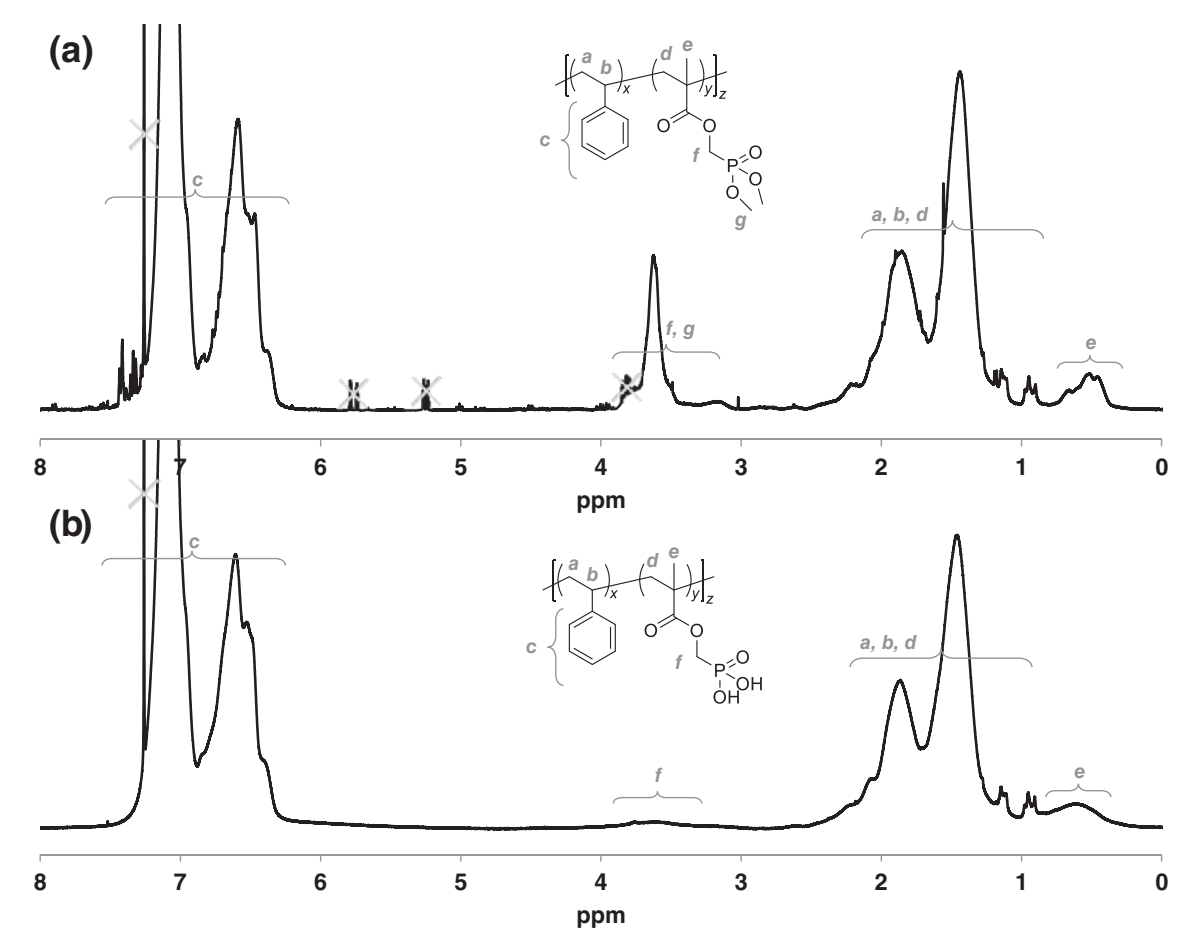

Figure 3. ${ }^{1} \mathrm{H}$ NMR spectra of purified products: (a) $\mathrm{P}\left(\mathrm{S}-\mathrm{co}-\mathrm{MAPC}_{1}\right)$; (b) $\mathrm{P}\left(\mathrm{S}-\mathrm{CO}-\mathrm{MAPC} \mathrm{C}_{1}(\mathrm{OH})_{2}\right)$.

\section{Scanning electron microscopy}

SEM was used to evaluate the morphology of the polymer blends and the localization of halloysite, before and after modification. For that, an environmental SEM Quanta 200 FEG (FEl Company) was operated under high vacuum at $15 \mathrm{kV}$. The samples prepared by cryo-fracture were coated with a thin carbon layer.

\section{Size distribution analysis}

Size distribution measurements were made on the extracted PA11 nodules using a Coulter LS 13230 (Coulter Beckmann Co.) laser diffraction particle size analyser instrument. The PA11 nodules were collected after dissolving the PS matrix using THF solvent and the size measurements were performed using the micro liquid module (MLM, $15 \mathrm{~mL}$ ) in THF with an obscuration of $10 \pm 2 \%$. At least two measurements were performed for each sample.

\section{Crystallization behaviour}

Crystallization behaviour of the blend formulations was investigated by DSC with a Pyris Diamond DSC (PerkinElmer Instruments) under nitrogen environment $\left(20 \mathrm{~mL} \mathrm{~min}^{-1}\right)$. Specimens of about $10 \mathrm{mg}$ were heated from 30 to $220^{\circ} \mathrm{C}$ at a rate of $10^{\circ} \mathrm{C} \mathrm{min}^{-1}$ (first heating scan), equilibrated at $220^{\circ} \mathrm{C}$ for $5 \mathrm{~min}$ then cooled at $10^{\circ} \mathrm{C} \mathrm{min}-1$ to $30^{\circ} \mathrm{C}$, equilibrated again at $30^{\circ} \mathrm{C}$, afterwards heated again (second heating scan) always at $10^{\circ} \mathrm{C} \mathrm{min}^{-1}$. The measurements were performed from cooling and second heating scans, whereas the first heating scan was made to eliminate the sample thermal history. Crystallization temperature $\left(T_{c}\right)$, melting temperature $\left(T_{m}\right)$ and melting enthalpy $\left(\Delta H_{m}\right)$ of the PA11 phase were determined. The degree of crystallinity $\left(X_{c}\right)$ of the PA11 phase was calculated using the following equation:

$$
X_{\mathrm{c}}=\frac{\Delta H_{\mathrm{m}}}{\Delta H_{\mathrm{m}}^{\mathrm{o}} \times w_{\mathrm{t}}}
$$

where $\Delta H_{\mathrm{m}}$ is the melting enthalpy, $\Delta H_{\mathrm{m}}^{\circ}$ the melting enthalpy of $100 \%$ crystalline polymer $\left(=206 \mathrm{~J} \mathrm{~g}^{-1}\right)^{49}$ and $w_{\mathrm{t}}$ the PA11 weight fraction in the composition.

\section{Rheological measurements}

Oscillatory shear measurements were performed using an advanced rheometric expansion system (ARES, TA Instruments). All the tests were carried out under nitrogen atmosphere on sample discs, which were dried under vacuum at $80^{\circ} \mathrm{C}$ for $24 \mathrm{~h}$. The measurements were performed at $240^{\circ} \mathrm{C}$ using the plate-plate geometry. The plate diameter was $25 \mathrm{~mm}$ and the gap between the two plates was set to $1 \mathrm{~mm}$. A shear strain of $5 \%$ was chosen for all subsequent frequency sweep tests. The frequency was varied from 0.07 to $100 \mathrm{rad} \mathrm{s}^{-1}$. A minimum of three specimens were tested for each formulation.

\section{RESULTS AND DISCUSSION Grafting characterization}

Before the characterization of the halloysite modified with the $\mathrm{P}\left(\mathrm{S}\right.$-co-MAPC ${ }_{1}(\mathrm{OH})_{2}$ ) copolymer, a ${ }^{1} \mathrm{H}$ NMR analysis was performed in order to characterize the grafting agent.

Figure 3 shows the ${ }^{1} \mathrm{H}$ NMR spectra of the purified products $\mathrm{P}\left(\mathrm{S}-\mathrm{CO}-\mathrm{MAPC}_{1}\right)$ and $\mathrm{P}\left(\mathrm{S}-\mathrm{CO}-\mathrm{MAPC}_{1}(\mathrm{OH})_{2}\right)$. The NMR spectrum of $\mathrm{P}\left(\mathrm{S}-\mathrm{CO}_{\mathrm{MAPC}}\right.$ ) (Fig. 3(a)) shows a large signal centred at $3.7 \mathrm{ppm}$ corresponding to the protons of the methylphosphonate groups carried by MAPC 1 units. This signal also exhibits a peak corresponding to the protons of the methylene group in $\alpha$-position of the phosphorus. A comparison between the intensity of this signal characteristic of MAPC $C_{1}$ units and the intensity of the signal centred at $6.9 \mathrm{ppm}$ characteristic of the aromatic protons of styrene units gives a molar percentage of about 5.4 for the phosphonated units. The spectrum of $\mathrm{P}\left(\mathrm{S}-\mathrm{CO}-\mathrm{MAPC}_{1}(\mathrm{OH})_{2}\right)$ (Fig. 3(b)) shows the disappearance of the $\mathrm{P}-\mathrm{O}-\mathrm{CH}_{3}$ protons and confirms the formation of phosphonic acid groups. 

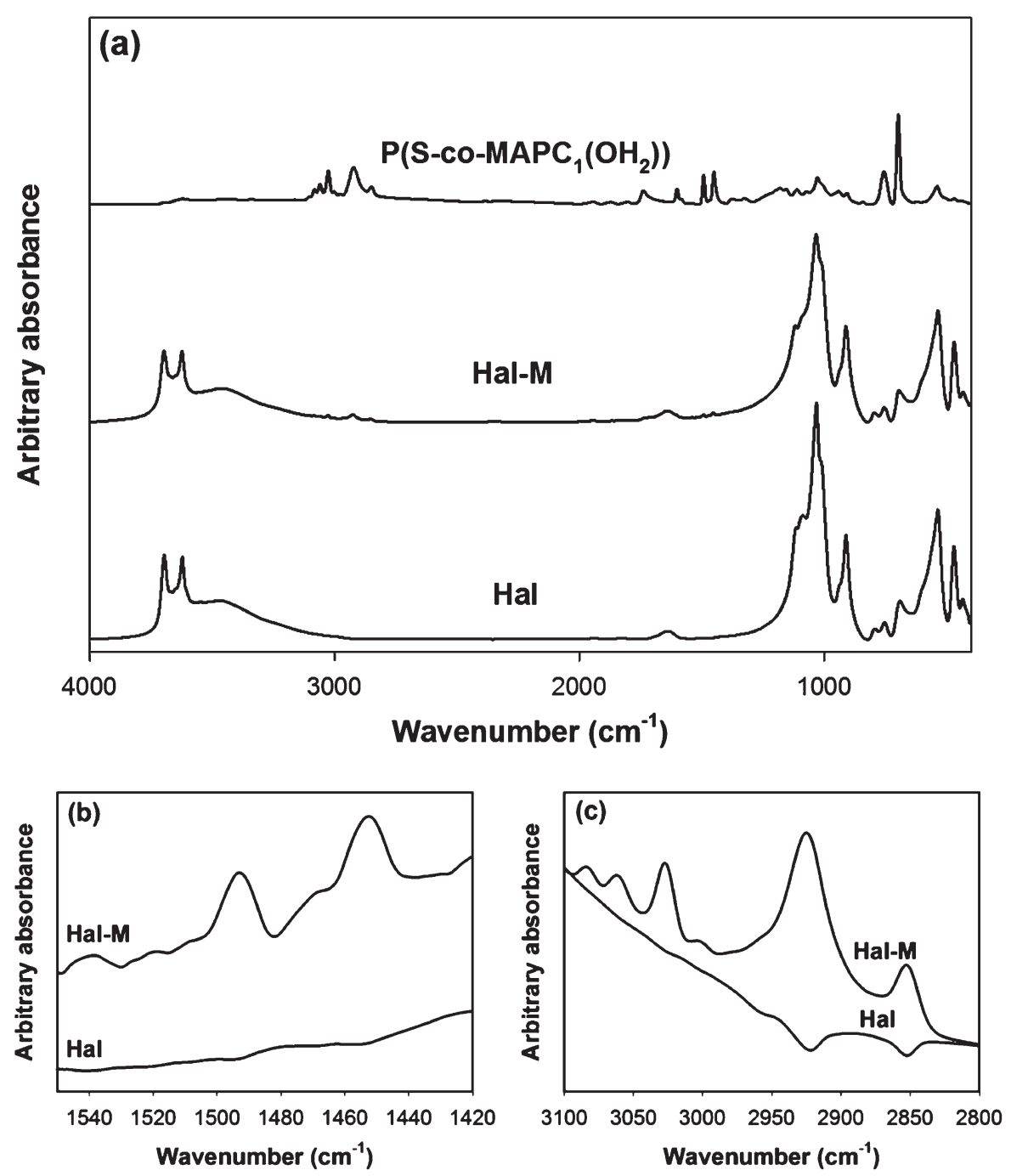

Figure 4. (a) FTIR spectra of Hal, Hal-M and $\mathrm{P}\left(\mathrm{S}-\mathrm{CO}-\mathrm{MAPC}_{1}(\mathrm{OH})_{2}\right)$, with (b) the $1400-1550 \mathrm{~cm}^{-1}$ region and (c) the methylene region of Hal and Hal-M.

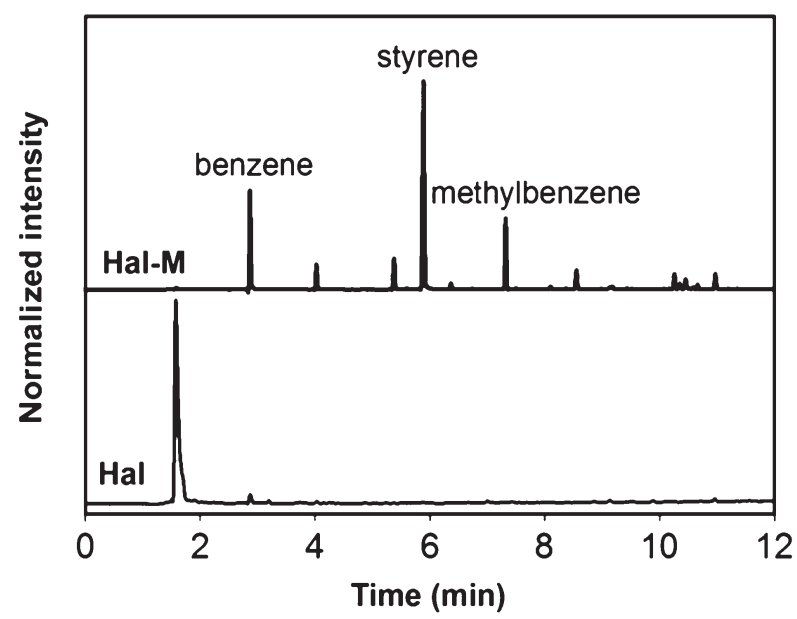

Figure 5. Py-GC/MS chromatograms of Hal and Hal-M.

Figure 4(a) shows the FTIR spectra of pristine halloysite, modified halloysite and $\mathrm{P}\left(\mathrm{S}-\mathrm{CO}-\mathrm{MAPC}_{1}(\mathrm{OH})_{2}\right)$ copolymer. At first view no differences between the chemical structures of $\mathrm{Hal}$ and $\mathrm{Hal}-\mathrm{M}$ are observed, but with a detailed view of the $1400-1550 \mathrm{~cm}^{-1}$ region (Fig. 4(b)) and methylene stretching region (Fig. 4(c)) we note the presence of new peaks for Hal-M. Indeed, in the first region, Hal-M exhibits bands at 1454 and $1492 \mathrm{~cm}^{-1}$ assigned to the characteristic $\mathrm{C}-\mathrm{H}$ bending of styrene, and in the methylene region the bands at 2852 and $2925 \mathrm{~cm}^{-1}$ are assigned to symmetric and asymmetric $\mathrm{C}-\mathrm{H}$ stretching, respectively. The observation of these chemical groups indicates the successful grafting of $\mathrm{P}\left(\mathrm{S}-\mathrm{CO}-\mathrm{MAPC}_{1}(\mathrm{OH})_{2}\right)$ on halloysite. The difficulty in observing these bands is due to the localization of the grafting at the inner surface. Indeed, the peak absorption shifts towards lower values due to the more constricted vibration of alkyl groups inside the confined spaces of halloysite lumen. ${ }^{41}$

Py-GC/MS was also used to obtain evidence for the grafting, and the results are presented in Fig. 5. The first observation on halloysite modification is the disappearance of the main observed peak for Hal that is attributed to sulfur contaminants. The elimination of these sulfur compounds can be due to clay purification through the grafting process. The chromatogram shows the appearance of several peaks corresponding to benzene, toluene, ethylbenzene, styrene, methylbenzene and indene. These compounds result from the decomposition of the grafted $\mathrm{P}\left(\mathrm{S}-\mathrm{CO}^{-\mathrm{MAPC}_{1}}(\mathrm{OH})_{2}\right)$ chains. 
(a)

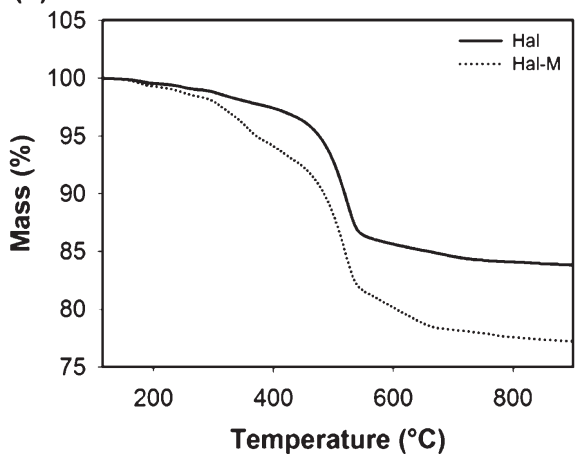

(b)

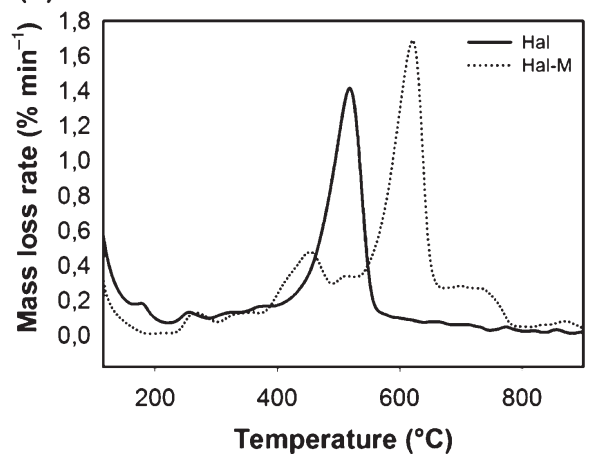

(c)

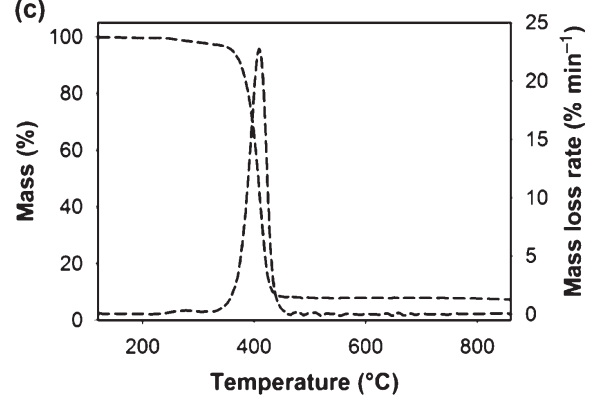

Figure 6. (a) TGA and (b) DTG curves of Hal and Hal-M. (c) TGA and DTG curves of P(S-co-MAPC $\left.1(\mathrm{OH})_{2}\right)$ copolymer.

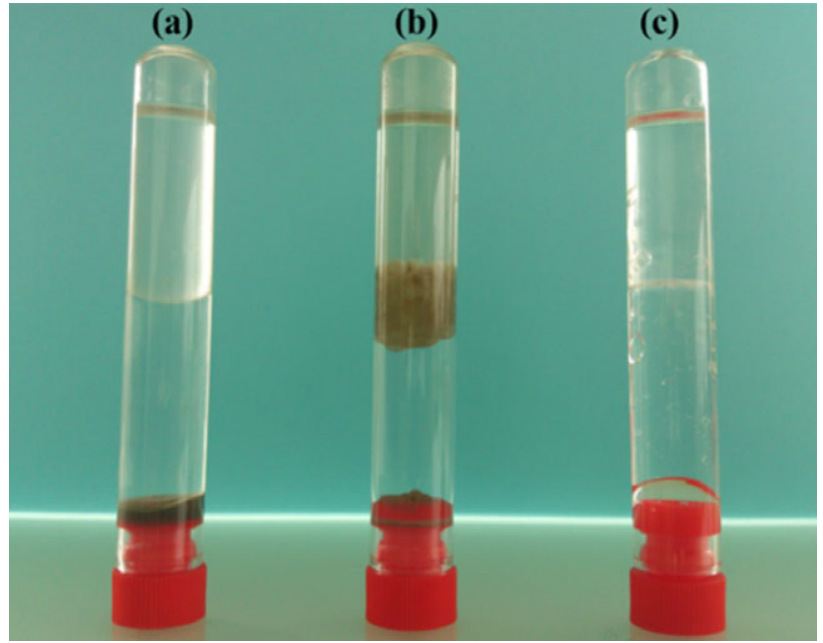

Figure 7. Dispersion stability of the HNTs in water-toluene mixture: (a) Hal; (b) Hal-M; (c) reference blend.

Figure 6 displays the TGA and differential thermogravimetric (DTG) curves of Hal, Hal-M and P(S-CO-MAPC $\left.{ }_{1}(\mathrm{OH})_{2}\right)$ copolymer. The mass loss in the range $40-220^{\circ} \mathrm{C}$ for both HNTs is due to the release of water adsorbed on the surface of the particles..$^{50,51}$ The continuous mass drop up to $450{ }^{\circ} \mathrm{C}$ for $\mathrm{Hal}$ is attributed to the loss of intercalated water molecules in the interlayer space. The more pronounced loss in the same range for Hal-M is attributed to the beginning of the decomposition of the grafted $\mathrm{P}\left(\mathrm{S}-\mathrm{CO}-\mathrm{MAPC}_{1}(\mathrm{OH})_{2}\right)$ chains, whereas the main part of this copolymer is decomposed at about $450^{\circ} \mathrm{C}$. Then, Hal sustains a mass loss of $11 \%$ between 410 and $560^{\circ} \mathrm{C}$ caused by the structural dehydroxylation of the hydroxyl groups of the inner surface, while this decomposition of the inner hydroxyl occurs in the range $530-660^{\circ} \mathrm{C}$ for Hal-M. We assume that this shift towards higher

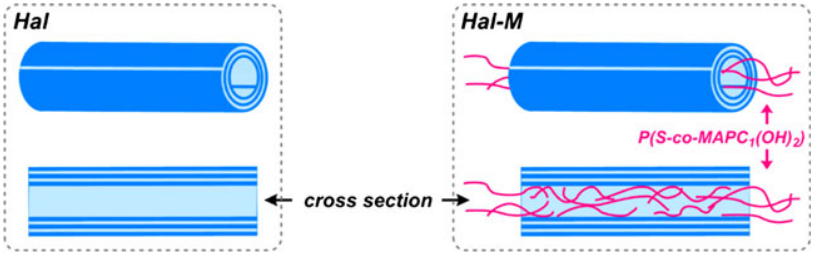

Figure 8. Schematic representation of halloysite lumen before and after $\mathrm{P}\left(\mathrm{S}-\mathrm{CO}-\mathrm{MAPC}_{1}(\mathrm{OH})_{2}\right)$ grafting.

values in the dehydroxylation temperature range is due to the reaction between the hydroxyl groups of halloysite inner surface and the phosphonic functions of $\mathrm{P}\left(\mathrm{S}-\mathrm{CO}-\mathrm{MAPC}_{1}(\mathrm{OH})_{2}\right)$. TGA was also used to quantify the grafting rate. Indeed, in the case of pristine halloysite the residue at $900^{\circ} \mathrm{C}$ is $83.9 \%$ while it is only $77.2 \%$ for $\mathrm{Hal}-\mathrm{M}$. This additional mass loss of $6.7 \%$ is related to the grafting of $\mathrm{P}\left(\mathrm{S}-\mathrm{CO}-\mathrm{MAPC}_{1}(\mathrm{OH})_{2}\right)$. Knowing that the $\mathrm{P}\left(\mathrm{S}-\mathrm{CO}-\mathrm{MAPC}_{1}(\mathrm{OH})_{2}\right)$ rate during the grafting procedure was $10 \mathrm{wt} \%$, the grafting success rate can be estimated to $67 \%$.

The grafting leads to a decrease of the free surface energy of halloysite, from 76.9 to $46.4 \mathrm{~mJ} \mathrm{~m}^{-2}$. To show the influence of this grafting on the surface energy of halloysite, a dispersion test in an immiscible water-toluene mixture was conducted. As shown in Fig. 7, Hal settles in the water bottom phase, whereas Hal-M segregates at the interface of water and toluene, and this suspension is still stable even after a week.

This change of affinity confirms the modification in the clay surface chemistry and consequently its polarity after grafting by $\mathrm{P}\left(\mathrm{S}-\mathrm{CO}-\mathrm{MAPC}_{1}(\mathrm{OH})_{2}\right)$. Indeed, due to the grafting of long copolymer chains inside the lumen of halloysite, some of these chains can emerge outside the lumen (Fig. 8) changing the surface energy of halloysite edges thus forming an amphiphilic system, the edges being nonpolar, whereas the outer surface remaining polar. 

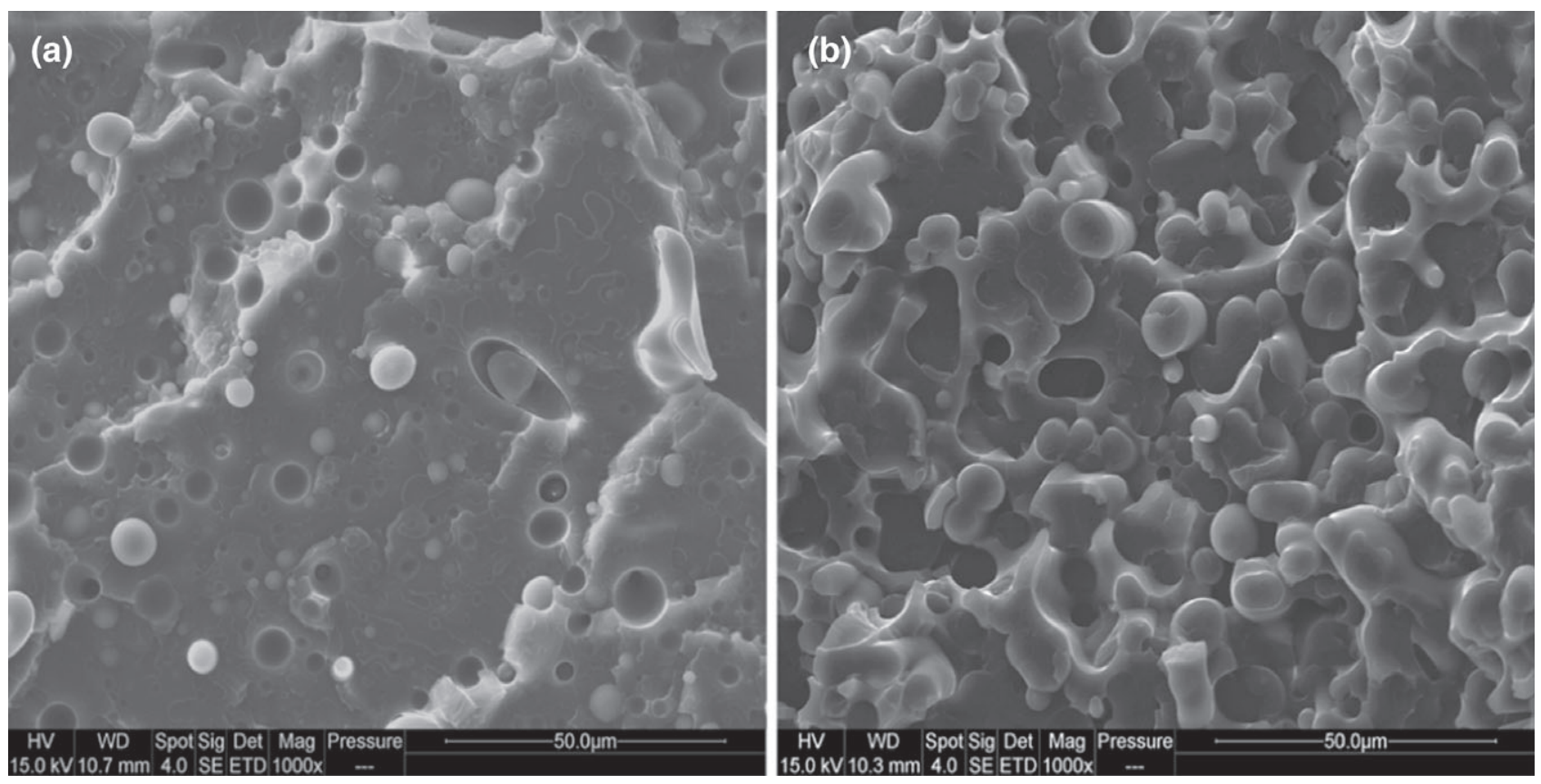

Figure 9. SEM topography micrographs of the unfilled (a) (80/20) and (b) (60/40) PS/PA11 blends.

\section{Morphology}

The morphology of the various systems was mainly studied using SEM. Figure 9 presents micrographs of the (80/20) and (60/40) unfilled blends. The micrographs show that the $(80 / 20)$ blend presents a matrix/dispersed phase morphology with PS as the matrix and PA11 as nodules, whereas the $(60 / 40)$ blend presents a co-continuous morphology, PA11 being more fluid than PS. These observations are in accordance with theoretical predictions of phase inversion. ${ }^{52}$

When halloysite has been added, focus was made on the PS/PA11 interface in order to examine in detail the filler location. Figure 10 displays SEM observations of PA 11 nodules in the $(80 / 20)$ blends filled at $3 \mathrm{wt} \%$. In $80 / 20 \mathrm{H} 3$, PA 11 nodules exhibit a smooth uniform surface due to the presence of all the HNTs inside the nodules, in contrast to $80 / 20 \mathrm{HM} 3$, where the nodules show a rough surface. This roughness is due to the presence of Hal-M at the nodule surface, as evidenced by the observations under back-scattered electrons mode. Indeed, $\mathrm{Hal}$ is concentrated in the nodule core because halloysite is only compatible with hydrophilic PA11. In contrast, Hal-M is clearly visible on the nodule surface, hence at the PS/PA11 interface in the 80/20 HM3 sample, confirming thus the amphiphilic behaviour of $\mathrm{Hal}-\mathrm{M}$ due to the presence of $\mathrm{P}\left(\mathrm{S}\right.$-co-MAPC $\left.(\mathrm{OH})_{2}\right)$ chains (Fig. 8). Indeed, bare halloysite totally migrates from PS matrix to dispersed PA11 phase, whereas modified halloysite segregates at the interface. It is well known that when nanoparticles are first dispersed in a polymer, the introduction of a second polymer with which the nanoparticles have better affinity will cause the migration of the nanoparticle into that second polymer. ${ }^{26,53}$ In our study, thermodynamically, the raw HNTs have a higher affinity with PA11 than with PS. Hence as the mixing process is performed for a sufficiently long time, the thermodynamically favourable state should be reached. In addition, PA11 nodules seem to be well covered (no decohesion at the interface) by the PS matrix revealing a better adhesion between PS matrix and PA11 nodules. Figure 11 displays micrographs of the $(60 / 40)$ blends filled with 10 wt\% of halloysite. Unsurprisingly, in the case of $60 / 40 \mathrm{H} 10$, all the HNTs are present in the PA11 phase. In addition, we observe a poor interfacial adhesion between PS and PA11. Nevertheless, in the presence of $10 \mathrm{wt} \%$ of $\mathrm{Hal}-\mathrm{M}$, the filler localization is changed. Indeed, in 60/40 HM10 we still observe HNTs in the PA11 phase, but with presence of some nanotubes in the PS phase (indicated with white circles in Fig. 11). This presence of Hal-M in the PS phase, despite its hydrophobicity, can be explained by the modification of the halloysite surface chemistry. The interface is also improved with addition of modified halloysite. These results are interesting especially because HNTs exhibits a high aspect ratio, leading to low interfacial stability with a high speed of transfer. Indeed, Göldel et al. ${ }^{54}$ characterized the final morphology of blends containing carbon nanotubes and carbon black by investigating the transfer of nanoparticles at the blend interface. They proved that the transfer of a high-aspect-ratio particle through the blend interface is faster than that of a low-aspect-ratio one. Moreover, carbon nanotubes have a very low tendency to segregate at the interface. Despite that, if they localize at the interface, they are always parallel to this interface (not perpendicular). In their article, they classified HNTs in 'high aspect ratio nano objects with fast transfer and low interfacial stability'.

To further confirm these changes in blend morphology, laser particle size analysis was performed to understand the effect of bare and modified halloysite on PA11 coalescence in the (80/20) blends. ${ }^{55}$ Figure 12 shows the size distribution of extracted PA11 nodules before and after annealing. Regarding the unfilled (80/20) blend, PA11 nodules exhibit a broad size distribution with the presence of spherical particles in the $0-10 \mu \mathrm{m}$ range and more elongated ones in the $10-40 \mu \mathrm{m}$ range. So, two different phenomena are observed after annealing. First, a coalescence process that concerns the small spherical nodules is seen through a decrease of the volume fraction of the small spherical nodules $(1-6 \mu \mathrm{m})$. Second, a relaxation process is seen of elongated nodules by an increase of the volume fraction of the largest PA11 nodules $(6-18 \mu \mathrm{m})$ with a shift and a refinement of the broad 

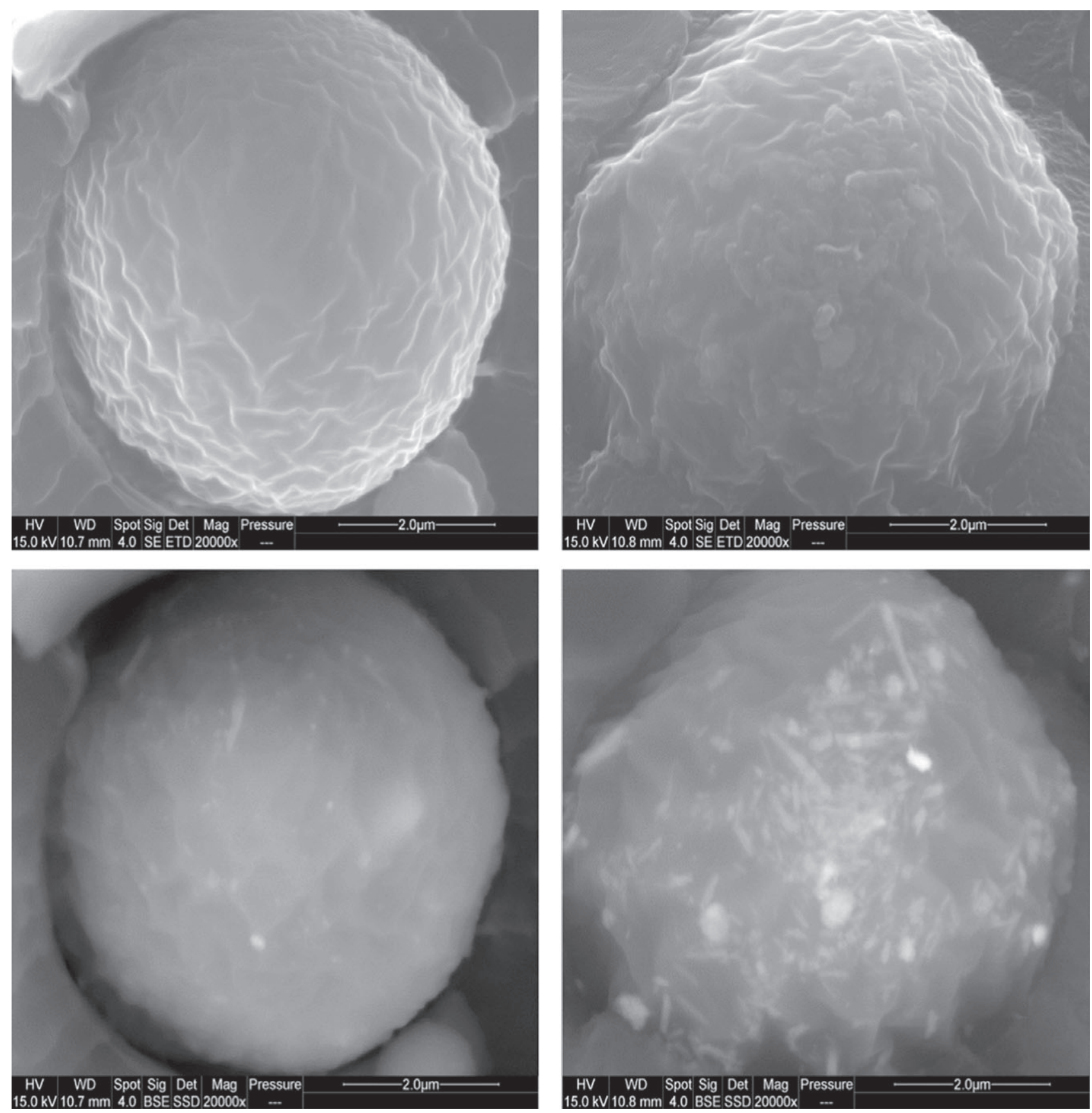

Figure 10. SEM observations of PA1 1 nodules in $80 / 20 \mathrm{H3}$ (left) and 80/20 HM3 (right) blends, under secondary electrons (top) and back-scattered electrons (bottom).

peak $(18-40 \mu \mathrm{m})$. With addition of 3 and $10 \mathrm{wt} \%$ of Hal, the system seems to be more disturbed, as the nodules exhibit an even broader size distribution with three peaks. The first one is still in the $0-10 \mu \mathrm{m}$ range corresponding to the spherical PA11 nodules, and in the 10-80 $\mu \mathrm{m}$ range an ' $\mathrm{M}$ '-shaped curve, typical of particles with high aspect ratio, can be seen. The lower and higher peaks correspond to lower and higher diameters of particles with high aspect ratio, respectively. ${ }^{56}$ After annealing, the same observations are made as for the unfilled blend with coalescence of the small nodules (especially for $80 / 20 \mathrm{H} 3$ ) and relaxation of the elongated ones. Finally, with incorporation of Hal-M in the blends, both initial size distribution and evolution of the morphology during annealing are affected. Indeed, PA11 nodules show a more uniform size distribution with smaller spherical particles in the $0.3-15 \mu \mathrm{m}$ range with fewer elongated nodules. After annealing, the volume fraction of the small nodules $(0.3-15 \mu \mathrm{m})$ remains almost the same with still relaxation of the elongated nodules. This coalescence inhibition is the result of the stabilization of the microstructure against annealing by the presence of nanotubes of $\mathrm{Hal}-\mathrm{M}$ at the PA1 1 nodules surface as seen in the SEM micrographs of Fig. 10.

\section{Thermal stability}

The TGA and DTG analysis for the (80/20) and (60/40) blends are shown in Figs 13 and 14, respectively. Firstly, we remark from the DTG curves that the decomposition of the blends 

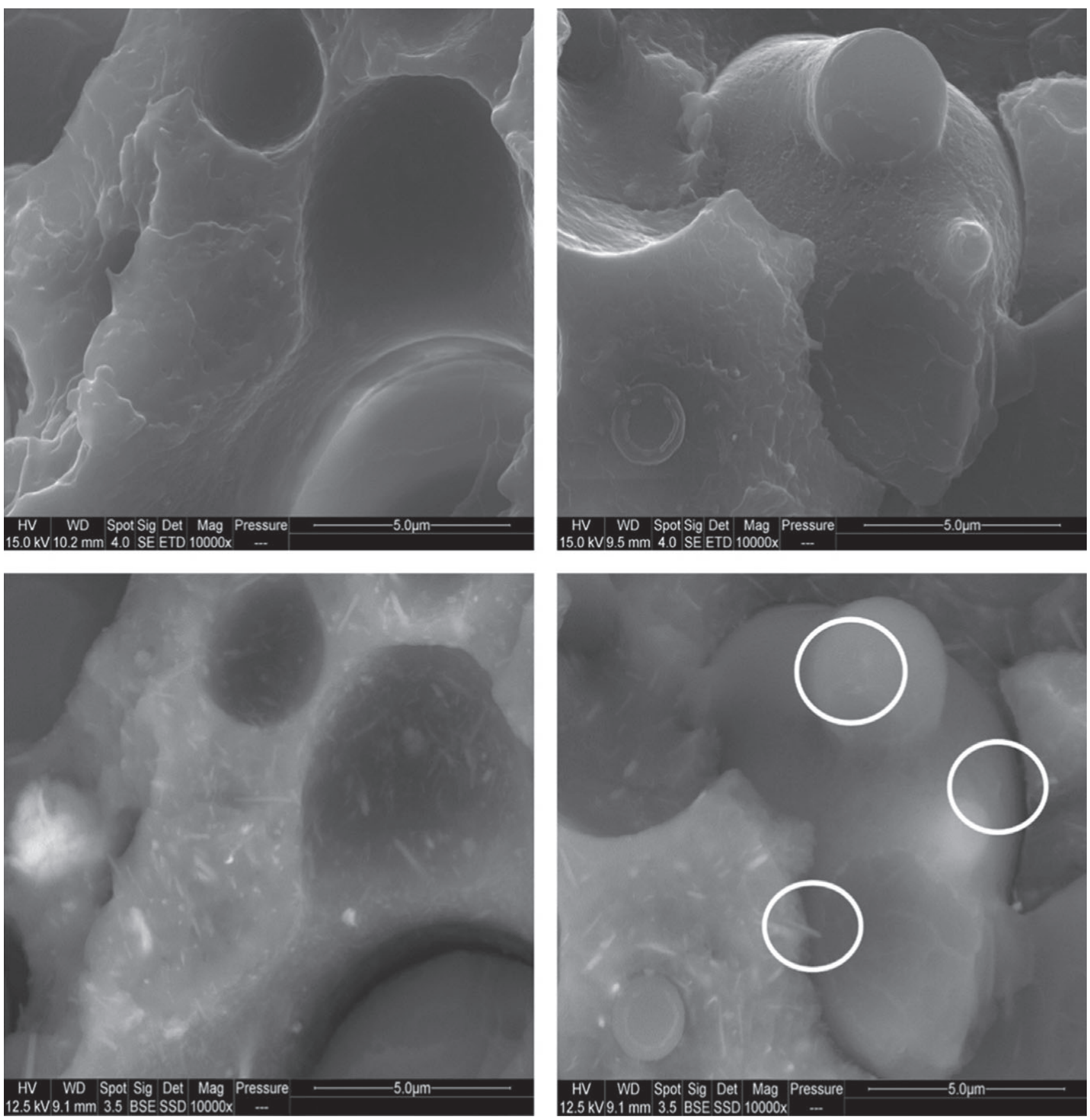

Figure 11. SEM observations of 60/40 H10 (left) and 60/40 HM10 (right) blends, under secondary electrons (top) and back-scattered electrons (bottom).

involves two steps, corresponding to the decomposition of PS and PA11, respectively. For the (80/20) blends (Fig. 13), the incorporation of both $\mathrm{Hal}$ and Hal-M does not improve the thermal stability of the PS phase because all the HNTs are in the PA11 phase. While the thermal stability of the PA11 phase is enhanced, but only with $3 \mathrm{wt} \%$ of Hal-M because of its localization at the interface. For $80 / 20 \mathrm{H} 10$ and $80 / 20 \mathrm{HM} 10$ the peak of the decomposition of the PA11 phase seems to be erased which can be due to the presence of a large amount of clay in the phase.

In the case of the (60/40) blends (Fig. 14), there is still an enhancement of the thermal stability of the PA11 phase upon incorporation of halloysite, but this time we also observe an effect on the PS phase. Indeed, in the 60/40 HM10 sample, the maximum degradation rate temperature increases from 389 to $400^{\circ} \mathrm{C}$, while it is only $388^{\circ} \mathrm{C}$ for $60 / 40 \mathrm{H} 10$. This is the confirmation of the presence of some Hal-M nanotubes in the PS phase as evidenced previously by the SEM observations (Fig. 11).

The enhancement of the thermal stability after halloysite inclusion is due to its intrinsic superior thermal stability which promotes polymer matrix stability via the formation of protecting chars during the decomposition process, and to its tubular structure with large lumen volume which allows entrapment of degradation products thus delaying mass transfer and increasing thermal stability of the polymer matrix. ${ }^{57}$ 

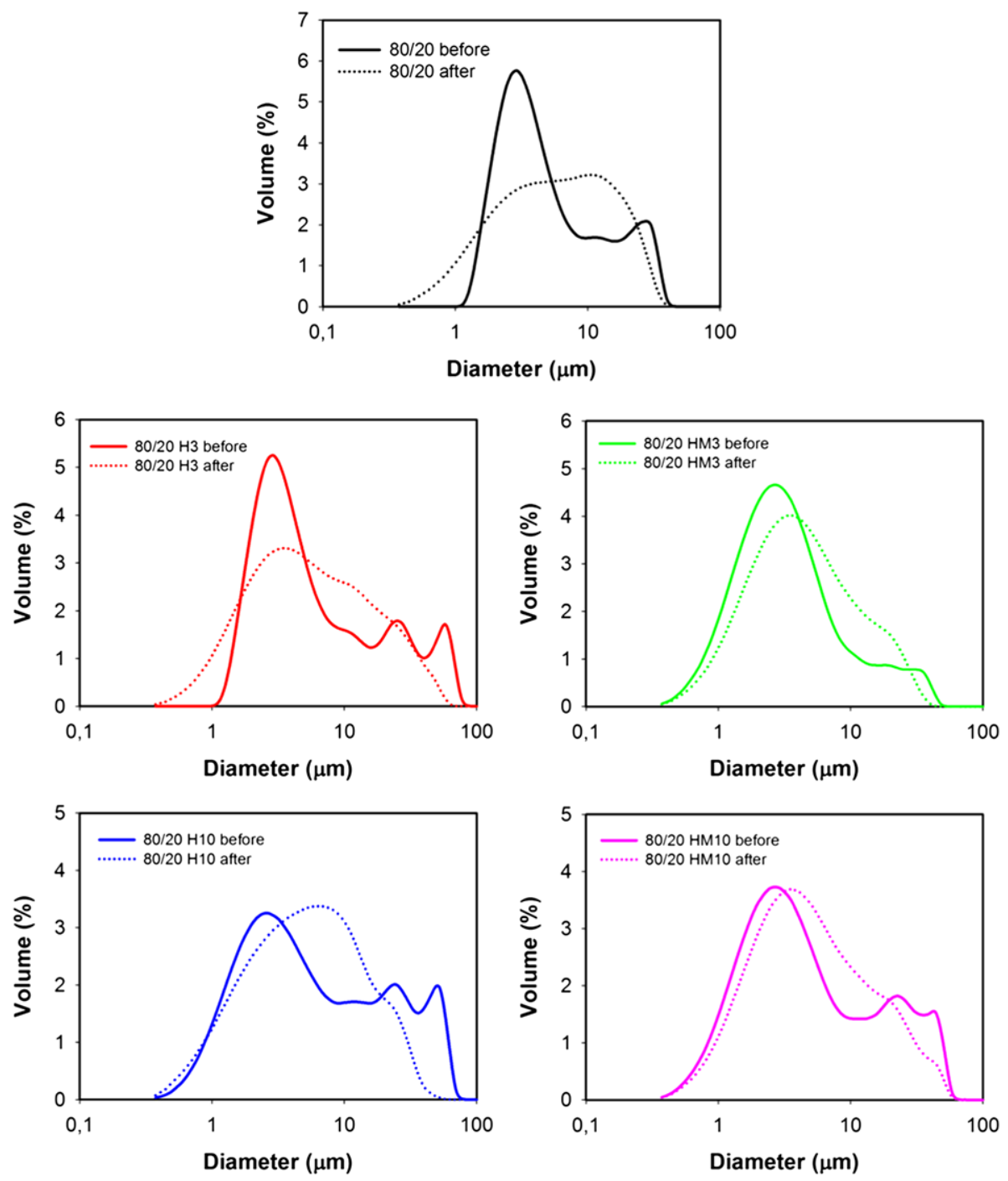

Figure 12. Size distribution of PA11 nodules in the (80/20) blends before annealing (solid curves) and after annealing (dotted curves).

(a)

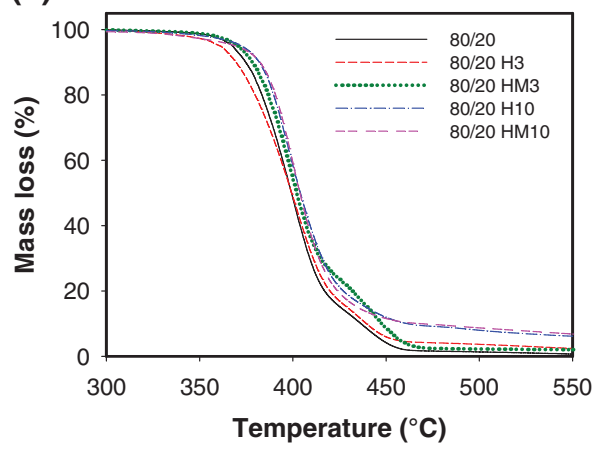

(b)

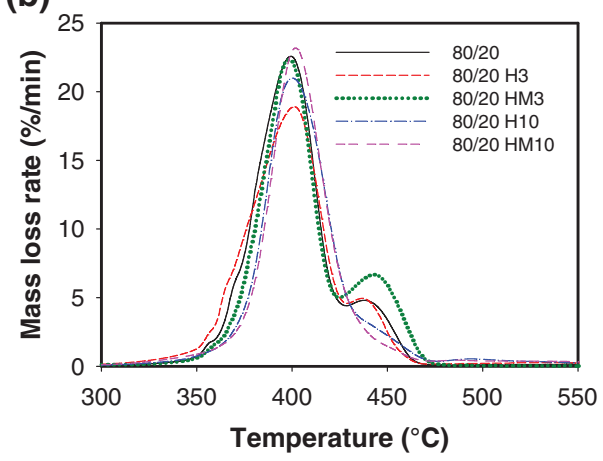

Figure 13. (a) TGA and (b) DTG curves of the (80/20) blends.

\section{Crystallization behaviour}

Crystallization temperature $\left(T_{c}\right)$, melting temperature $\left(T_{m}\right)$ and calculated crystallinity $\left(X_{c}\right)$ of the various formulations are reported in Table 2. The results show no difference between the unfilled (80/20) and (60/40) blends, which indicates that PA11 crystallization is not affected by its phase morphology in the blend. However, the presence of halloysite affects the crystallization of the PA11 phase. Indeed, a nucleating effect is observed through an increase in $T_{c}$, particularly for blends filled at $10 \mathrm{wt} \%\left(+6.6^{\circ} \mathrm{C}\right.$ for example in $\left.80 / 20 \mathrm{H} 10\right)$. Nevertheless, no effects of halloysite modification are noted. This nucleating activity does not lead to increases in terms of crystallinity while the melting behaviour remains unaltered whatever the composition. 
(a)

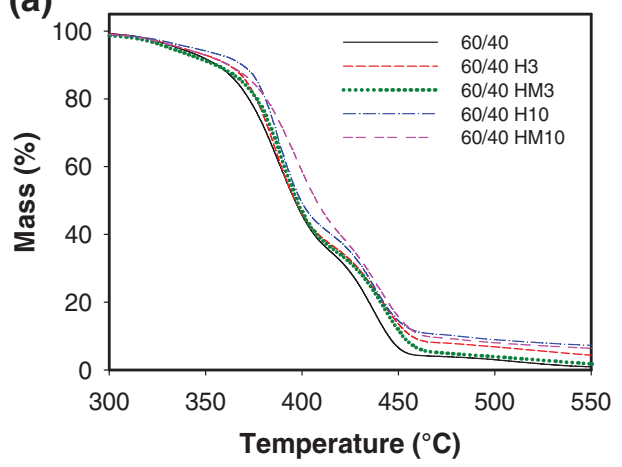

(b)

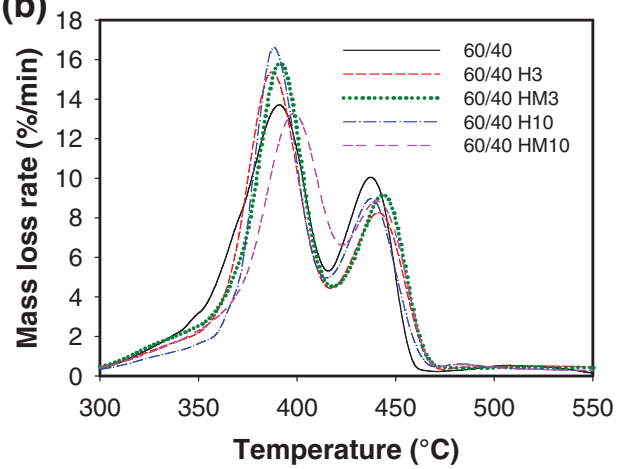

Figure 14. (a) TGA and (b) DTG curves of the (60/40) blends.

(a)

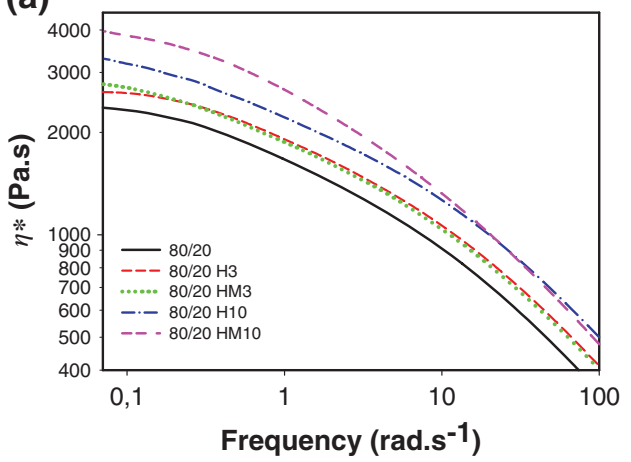

(b)

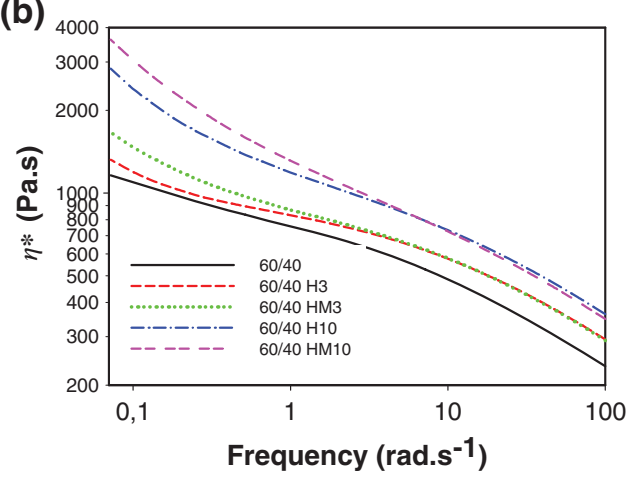

Figure 15 . Complex viscosity versus frequency of (a) (80/20) blends and (b) (60/40) blends.

Table 2. $T_{m}, T_{c}$ and $X_{c}$ values of the various PS/PA11 composites

\begin{tabular}{|lccc|} 
Sample & $T_{\mathrm{m}}\left({ }^{\circ} \mathrm{C}\right)$ & $T_{\mathrm{c}}\left({ }^{\circ} \mathrm{C}\right)$ & $X_{\mathrm{c}}(\%)$ \\
\hline $80 / 20$ & $191.1 \pm 0.9$ & $165.9 \pm 0.8$ & $20.1 \pm 0.2$ \\
$80 / 20 \mathrm{H3}$ & $189.9 \pm 1.1$ & $167.6 \pm 0.3$ & $19.5 \pm 1$ \\
$80 / 20 \mathrm{HM} 3$ & $191.9 \pm 0.7$ & $166.8 \pm 0.7$ & $19.7 \pm 0.9$ \\
$80 / 20 \mathrm{H} 10$ & $189.6 \pm 0.1$ & $172.5 \pm 0.3$ & $19 \pm 1$ \\
$80 / 20 \mathrm{HM} 10$ & $191.9 \pm 0.7$ & $169.1 \pm 0.3$ & $19.3 \pm 0.1$ \\
$60 / 40$ & $193.8 \pm 1.5$ & $165.2 \pm 0.7$ & $19.3 \pm 0.54$ \\
$60 / 40 \mathrm{H3}$ & $193.2 \pm 0.2$ & $168.4 \pm 0.2$ & $20.3 \pm 0.2$ \\
$60 / 40 \mathrm{HM} 3$ & $191.5 \pm 0.7$ & $166.7 \pm 0.3$ & $18.9 \pm 0.2$ \\
$60 / 40 \mathrm{H} 10$ & $191.5 \pm 0.6$ & $171.3 \pm 0.2$ & $19.9 \pm 0.4$ \\
$60 / 40 \mathrm{HM} 10$ & $193.8 \pm 1.2$ & $170.2 \pm 0.7$ & $19.8 \pm 0.6$ \\
\hline
\end{tabular}

\section{Rheological behaviour}

Complex viscosity $\left(\eta^{*}\right)$ and shear storage modulus of all samples are shown in Figs 15 and 16, respectively. One can note that the $(80 / 20)$ blends exhibit higher values of $\eta^{*}$ than the $(60 / 40)$ ones because PS is more viscous than PA11. The $(80 / 20)$ blends (Fig. 15(a)) exhibit a typical shear thinning behaviour with the appearance of a Newtonian plateau at low frequency (liquid-like behaviour) and no difference in this behaviour can be seen when $3 \%$ of raw or modified halloysites is added. Nevertheless, at $10 \mathrm{wt} \%$ of HNTs, we notice that the viscosity is even increased and the $80 / 20$ HM10 sample has a higher viscosity than $80 / 20 \mathrm{H} 10$ at medium and low frequencies (only in the $0.07-10 \mathrm{rads}^{-1}$ frequency range).
However, as seen in Fig. 16(b), the (60/40) compositions filled with halloysite exhibit a gel-like behaviour at low frequencies $\left(0.07-5 \mathrm{rad} \mathrm{s}^{-1}\right)$, especially for the $60 / 40 \mathrm{HM} 10$ sample, that is evidenced by the appearance of a plateau in the $G^{\prime}$ versus frequency plot. This gel-like behaviour is attributed to the formation a solid network of nanofillers due to the interfacial adhesion between the polymers and HNTs that restricts the polymer chains flow in the molten state. ${ }^{10}$ The compositions also possess higher values of complex viscosity (Fig. 15(b)) than the corresponding unfilled blends, as filler content increases. While, at higher frequency $\left(5-100 \mathrm{rad} \mathrm{s}^{-1}\right)$, the effect of the modification does not appear. This increase of complex viscosity at low frequency is due to the particle-particle interaction or drop-drop hydrodynamic interaction and particle-induced clustering, ${ }^{53}$ whereas the rheological behaviour is dominated by the polymer rather than the nanofillers at higher frequencies.

\section{CONCLUSIONS}

Halloysite selective modification was successfully achieved via grafting of $\mathrm{P}\left(\mathrm{S}-\mathrm{CO}-\mathrm{MAPC}_{1}(\mathrm{OH})_{2}\right)$ copolymer chains at the inner surface. FTIR, TGA, Py-GC/MS and solubility test results evidenced this grafting with a change in surface chemistry, the halloysite becoming amphiphilic after its functionalization. The influence of halloysite modification on the morphology of two PS/PA11 blends (80/20 and 60/40) was examined. SEM micrographs revealed a change in halloysite location after modification as the HNTs migrate from the core of the PA11 phase to the PS/PA11 interface. This inhibits the coalescence process as evidenced by laser particle size analysis of extracted PA11 nodules before and after 
(a)

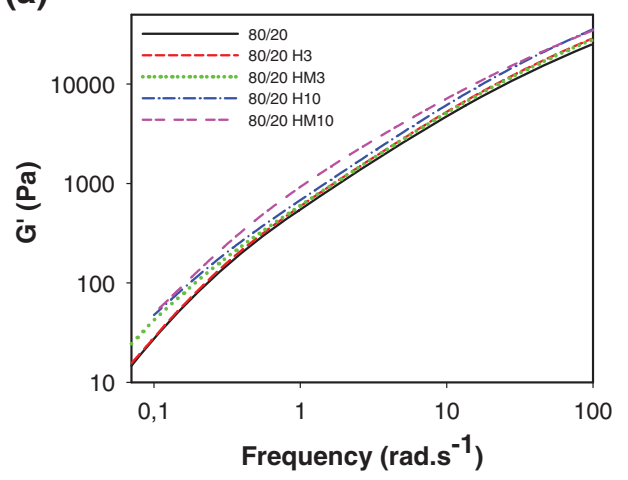

(b)

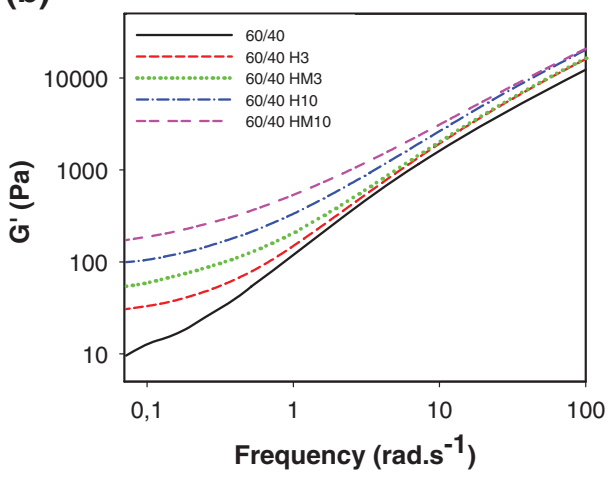

Figure 16. Shear storage modulus versus frequency of (a) (80/20) blends and (b) (60/40) blends.

annealing. Since in the $60 / 40$ blends, Hal-M is present at the interface with some nanotubes in the PS phase as confirmed by TGA, the thermal stability of the PS phase is enhanced due to the presence of some Hal-M nanoparticles. DSC results showed that both $\mathrm{Hal}$ and Hal-M act as nucleating agents. Finally, rheological measurements showed the limited effect of the modification on the rheology of the (80/20) compositions, while Hal-M enhances the gel-like behaviour observed in the filled $(60 / 40)$ blends.

\section{ACKNOWLEDGEMENTS}

The authors are grateful to EGIDE for its financial support through the Tassili program 13MDU891, to Jean-Jacques Flat from Arkema and to the Algerian company Soalka for supplying polyamide-11 and raw Algerian halloysite, respectively. MS is also grateful to Loic Dumazert for his help in the experimental work.

\section{REFERENCES}

1 Sionkowska A, Prog Polym Sci 36:1254-1276 (2011).

2 Utracki L, Polymer Blends Handbook. Springer, Dordrecht (2002).

3 Park CD, Jo WH and Lee MS, Polymer 37:3055-3063 (1996).

4 Koning C, Prog Polym Sci 23:707-757 (1998).

5 Veenstra $H$, van Lent BJJ, van Dam J and de Boer AP, Polymer 40:6661-6672 (1999).

6 Zhang C-L, Feng L-F, Gu X-P, Hoppe S and Hu G-H, Polymer 48:5940-5949 (2007).

7 Xanthos M and Dagli SS, Polym Eng Sci 31:929-935 (1991).

8 Tol RT, Groeninckx G, Vinckier I, Moldenaers P and Mewis J, Polymer 45:2587-2601 (2004).

9 Elias L, Fenouillot F, Majesté JC, Alcouffe P and Cassagnau P, Polymer 49:4378-4385 (2008).

10 Elias L, Fenouillot F, Majeste JC and Cassagnau P, Polymer 48:6029-6040 (2007).

11 Yang J, Feng C, Dai J, Zhang N, Huang T and Wang Y, Polym Int 62:1085-1093 (2013).

12 Li W, Karger-Kocsis J and Thomann R, J Polym Sci B: Polym Phys 47:1616-1624 (2009).

13 Chen G, Kim H, Kim E and Yoon J, Polymer 46:11829-11836 (2005).

14 Dasari A, Yu Z, Yang M and Zhang Q, Compos Sci Technol 66:3097-3114 (2006).

15 Wang K, Wang C, Li J, Su J, Zhang Q, Du R et al., Polymer 48:2144-2154 (2007).

16 Chiu F-C, Lai S-M, Chen Y-L and Lee T-H, Polymer 46:11600-11609 (2005).

17 Borah JS and Chaki TK, Thermochim Acta 529:45-50 (2012).

18 Lipatov YS and Nesterov AE, Polym Eng Sci 32:1261-1263 (1992).

19 Taguet A, Cassagnau P and Lopez-Cuesta J-M, Prog Polym Sci 39:1526-1563 (2014).

20 Gubbels F, Blacher S, Vanlathem E, Jerome R, Deltour R, Brouers F et al., Macromolecules 28:1559-1566 (1995).
21 Fang Z, Harrats C, Moussaif N and Groeninckx G, J Appl Polym Sci 106:3125-3135 (2007).

22 Zhang L, Wan C and Zhang Y, Polym Eng Sci 49:209-216 (2009).

23 Ali Z, Le HH, Ilisch S, Thurn-Albrecht T and Radusch HJ, Polymer 51:4580-4588 (2010).

24 Gubbels F, Jerome R, Vanlathem E, Deltour R, Blacher S and Brouers F, Chem Mater 10:1227-1235 (1998).

25 Feng J, Chan CHM and Li J, Polym Eng 43:1058-1063 (2003).

26 Elias L, Fenouillot F, Majesté JC, Martin G and Cassagnau P, J Polym Sci B: Polym Phys 46:1976-1983 (2008).

27 Liebscher $M$, Tzounis L, Pötschke $P$ and Heinrich G, Polymer 54:6801-6808 (2013).

28 Knauert ST, Douglas JF and Starr FW, J Polym Sci B: Polym Phys 45:1882-1897 (2007).

29 Borah JS, Karak N and Chaki TK, Mater Sci Eng A 528:2820-2830 (2011).

30 Kelarakis A, Giannelis EP and Yoon K, Polymer 48:7567-7572 (2007).

31 Subramanian S and Lee S, Polym Eng Sci 39:2274-2281 (1999).

32 Lu X and Weiss R, Macromolecules 24:4381-4385 (1991).

33 Jo WH, Park CD and Lee MS, Polymer 37:1709-1714 (1996).

34 Pei A, Liu A, Xie T and Yang G, Macromol Chem Phys 207:1980-1985 (2006).

35 Parpaite T, Otazaghine B, Caro AS, Taguet A, Sonnier R and Lopez-Cuesta JM, Polymer 90:34-44 (2016).

36 Deyrail Y, Mighri F, Bousmina M and Kaliaguine S, Fuel Cells 7:447-452 (2007).

37 Du M, Guo B and Jia D, Polym Int 59:574-582 (2010).

38 Handge U, Hedicke-Höchstötter $\mathrm{K}$ and Altstädt V, Polymer 51:2690-2699 (2010).

39 Prashantha K, Schmitt H, Lacrampe MF and Krawczak P, Compos Sci Technol 71:1859-1866 (2011).

40 Lecouvet B, Sclavons M, Bourbigot S and Bailly C, Polym Adv Technol 25:137-151 (2014).

41 Yah WO, Takahara A and Lvov YM, J Am Chem Soc 134:1853-1859 (2012).

42 Yah WO, Xu H, Soejima H, Ma W, Lvov Y and Takahara A, J Am Chem Soc 134:12134-12137 (2012).

43 Pal P, Kundu MK, Malas A and Das CK, J Appl Polym Sci 131:39587 (2014).

44 Kundu MK, Pal P, Hatui G, Das CK and Kalra SS, J Polym Res 22:29 (2015).

45 Lin T, Zhu L, Chen T and Guo B, J Appl Polym Sci 129:47-56 (2013).

46 El Asri Z, Chougrani K, Negrell-Guirao C, David G, Boutevin B and Loubat C, J Polym Sci A: Polym Chem 46:4794-4803 (2008).

47 Dorez G, Otazaghine B, Taguet A, Ferry L and Lopez-Cuesta JM, Polym Int 63:1665-1673 (2014).

48 Owens DK and Wendt RC, J Appl Polym Sci 13:1741 - 1747 (1969).

49 Mago G, Kalyon DM and Fisher FT, J Polym Sci B: Polym Phys 49:1311-1321 (2011).

50 Kadi S, Lellou S, Marouf-Khelifa K, Schott J, Gener-Batonneau I and Khelifa A, Micropor Mesopor Mater 158:47-54 (2012).

51 Rozynek Z, Zacher T, Janek M, Čaplovičová M and Fossum JO, Appl Clay Sci 77-78:1-9 (2013). 
52 Steinmann S, Gronski W and Friedrich C, Polymer 42:6619-6629 (2001).

53 Fenouillot F, Cassagnau P and Majesté JC, Polymer 50:1333-1350 (2009).

54 Göldel A, Marmur A, Kasaliwal GR, Pötschke P, Heinrich G, Göldel A et al., Macromolecules 44:6094-6102 (2011).
55 Lyu S, Jones TD, Bates FS and Macosko CW, Macromolecules 35:7845-7855 (2002).

56 Parpaite T, Otazaghine B, Taguet A, Sonnier R, Caro AS and Lopez-Cuesta JM, Polymer 55:2704-2715 (2014).

57 Du M, Guo B and Jia D, Eur Polym J 42:1362-1369 (2006). 